\title{
Speed profile optimization of an electrified train in cat linh-ha dong metro line based on pontryagin's maximum principle
}

\author{
An Thi Hoai Thu Anh ${ }^{1}$, Nguyen Van Quyen ${ }^{2}$, Nguyen Thanh Hai ${ }^{3}$ \\ Nguyen Van Lien ${ }^{4}$, Vu Hoang Phuong ${ }^{5}$ \\ ${ }^{1}$ Department of Electrical Engineering, University of Transport and Communications, Vietnam \\ ${ }^{2}$ Department of Applied Mechanics, Hanoi University of Science and Technology, Vietnam \\ ${ }^{3}$ Department of Electronics Engineering, University of Transport and Communications, Vietnam \\ ${ }^{4,5}$ Department of Industrial Automation, Hanoi University of Science and Technology, Vietnam
}

\section{Article Info}

Article history:

Received Dec 8, 2018

Revised Apr 25, 2019

Accepted Jul 17, 2019

\section{Keywords:}

Automatic train operation Energy efficient operation Pontryagin's maximum principle Speed profile optimization Urban rail systems

\begin{abstract}
An urban railway is a complex technical system that consumes large amounts of energy, but this means of transportation still has been obtained more and more popularity in densely populated cities because of its features of highcapacity transportation capability, high speed, security, punctuality, lower emission, reduction of traffic congestion. The improved energy consumption and environment are two of the main objectives for future transportation. Electrified trains can meet these objectives by the recuperation and reuse of regenerative braking energy and by the energy - efficient operation. Two methods are to enhance energy efficiency: one is to improve technology (e.g., using energy storage system, reversible or active substations to recuperate regenerative braking energy, replacing traction electric motors by energy-efficient traction system as permanent magnet electrical motors; train's mass reduction by lightweight material mass...); the other is to improve operational procedures (e.g. energy efficient driving including: ecodriving; speed profile optimization; Driving Advice System (DAS); Automatic Train Operation (ATO); traffic management optimization...). Among a lot of above solutions for saving energy, which one is suitable for current conditions of metro lines in Vietnam. The paper proposes the optimization method based on Pontryagin's Maximum Principle (PMP) to find the optimal speed profile for electrified train of Cat Linh-Ha Dong metro line, Vietnam in an effort to minimize the train operation energy consumption.
\end{abstract}

Copyright (c) 2020 Institute of Advanced Engineering and Science. All rights reserved.

\section{Corresponding Author:}

An Thi Hoai Thu Anh,

Department of Electrical Engineering,

University of Transport and Communications,

$\mathrm{N}^{0} 3$ Cau Giay, Lang Thuong Commune, Dong Da District, Hanoi, Vietnam.

Email: htanh.ktd@utc.edu.vn

\section{INTRODUCTION}

Recent years, traffic jam and environmental pollution in metropolitan areas have raised concerns over nations worldwide. Under the circumstances, the urban railway transit seems to be an outstanding solution to reduce the adverse effects of urban mobility because of its large transport capacity, safety, reliability and significantly environmental pollution reduction [1]. In developing countries like Vietnam, dozens of metro lines are going to and getting be built in Hanoi, and Ho Chi Minh cities with a total rout length about $500 \mathrm{~km}$. However, metro systems consume huge amounts of energy, proposing saving energy has considerable impacts on the cost reduction for urban railway systems. 
There are many ways to reduce the energy consumption in urban railway systems including: recuperating regenerative braking energy through timetable optimization to synchronize braking and accelerating phases of trains [2-11] or using energy storage systems and reversible, active substations to back energy to line utility [12-18]; reducing the losses in power supplies, traction drive system, converters, lines [19-21]; energy-efficient driving by optimizing the speed profile [22-31]. Among these solutions, optimizing the speed profile of each train has been done research extensively [32] because of being suitable for existing metro lines, saving significant energy with relatively low capital investment without improving or building new infrastructure.

All most of metro lines are getting under way in Vietnam not to be equiped regenerative braking energy recuperation devices, and the braking energy will dissipate on braking resistors to cause energy waste. However, using several solutions for saving energy such as: substituting diod recrifiers by resersable/active converters in traction substations or installing energy storage devices to recuperate the braking enregy are too expensive and squandered because meterial facilities of the metro lines have just been invested in, so the equipment replacement is not suitable for Metro lines in Viet nam in the comming time. With reasons analysed above, so using the optimal control theory [33] comprising of Pontryagin's Maximum Principle (PMP), Dymamic Programming (DP) [34], Mixed Integer Linear Programming (MILP) [35] finding the optimal speed profile applied to every train is the best solution to minimize the train operation energy consumption without any changes about infrustructure, equipment. The paper proposes one of these methods, namely; using Pontryagin's Maximum Principle for Cat Linh - Ha Dong metro line in Vietnam. Simulation results are presented and showed the effectiveness of optimal control method - PMP in saving energy of train operation up to $10,8 \%$.

\section{MODELLING MOTION OF TRAIN}

The train is regarded as a particle and kinematic equation can be represented by the following continuous - space model [5]

$$
\left\{\begin{array}{l}
\frac{d x}{d t}=v \\
m v \frac{d v}{d x}=F_{t r}(v)-F_{b r}(v)-W_{0}(v)-F_{g r a d}(x)
\end{array}\right.
$$

where $v, t, x, m$ represent respectively train speed $(m / s)$, operation time $(s)$, train position $(m)$, full load translating mass of train (tone) and $F_{t r}, F_{b r}, W_{0}, F_{\text {grad }}$ are traction, electrical braking, resistance, gradient resistance forces applied on the train. These forces are shown in Figure 1.

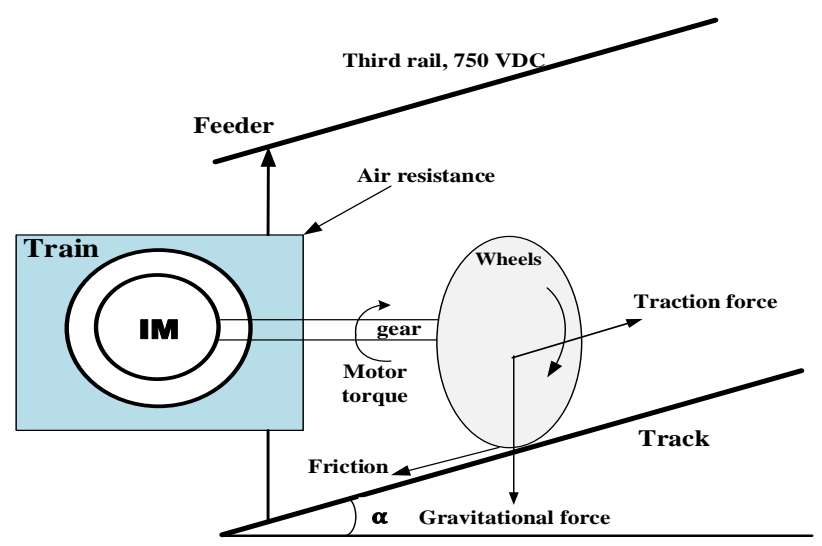

Figure 1. Torques and forces act on the rail wheel

Base on curves of traction force $F_{t r}$, braking force $F_{b r}$ given by manufacturers [36], Using the identification method to find traction, braking characteristic curves in Figure 2, Figure 3, and the Least Square method to find equivalent polynomials. 


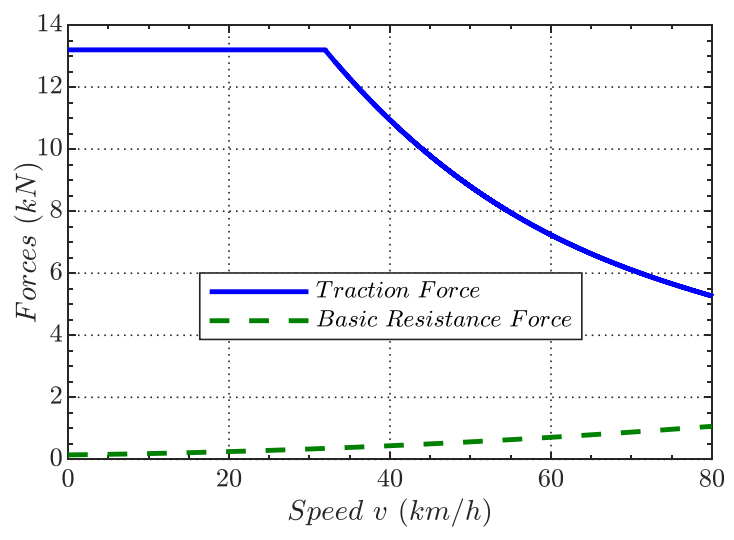

Figure 2. Maximum traction characteristic curve per motor

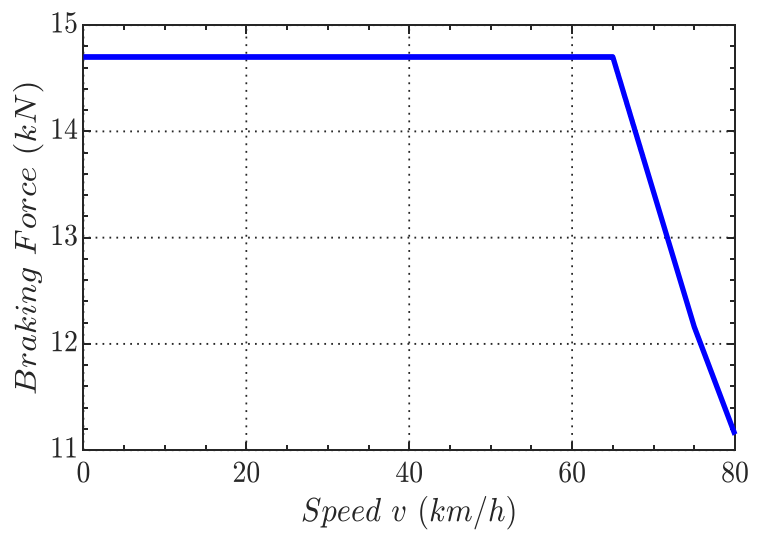

Figure 3. Maximum braking characteristic curve per motor

The maximum traction and maximum braking forces corresponding to the speed $v$ are

$$
\begin{aligned}
& F_{t r}= \begin{cases}13.2 & (0 \leq v \leq 32) \\
-2.5 \cdot 10^{-5} v^{3}+0.007 \cdot v^{2}-0.66 v+28.35 & (32<v \leq 80)\end{cases} \\
& F_{b r}= \begin{cases}14.7 & (0 \leq v \leq 65) \\
-0.254 v+31.21 & (65<v \leq 75) \\
-0.2027 v+27.36 & (75<v \leq 80)\end{cases}
\end{aligned}
$$

Figure 2 shows forces acting on the train in which the resistance force comprises of the air resistance, the friction resistance. The basic resistance $w_{0}$ can be calculated by using Davis formula [37]

$$
w_{0}=\frac{W_{0}}{m}=a+b v+c v^{2}
$$

where $a, b, c$ are coefficients of train's resistance.

The gradient force $F_{\text {grad }}$ caused by slope of road: $F_{\text {grad }}=m g \sin \alpha$

where $g, \alpha$ are the gravity acceleration and the rail track slope respectively.

\section{SPEED TRAJECTORY OPTIMALITY ANALYSIS BASED ON PMP AND ENERGY ASSUMPTION}

Depending on the long or short distance between stations, a train operates in three or four phases. Some studies showed optimal sequence modes of the train to save operation energy; with the short station, the train runs in three phases: accelerating, coasting, braking; with the long station; the train runs in 4 phases: Accelerating, cruising, coasting, braking phase [24], and shown Figure 4, Figure 5. Forces have acted on a train in operation modes are different; accelerating process acted by tractive force, and basic resistance force; cruising process acted by tractive force, and basic resistance force; coasting process has only basic resistance force, braking process with braking force, and basic resistance force. 


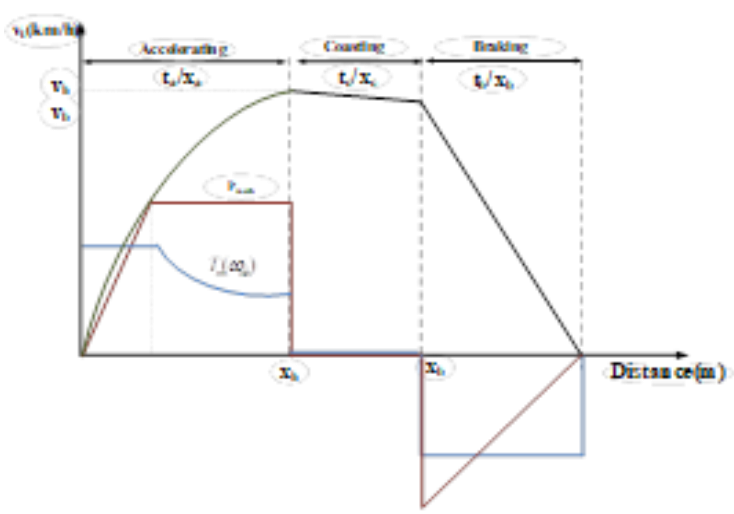

Figure 4. Optimal sequence modes of the train movement with a short station

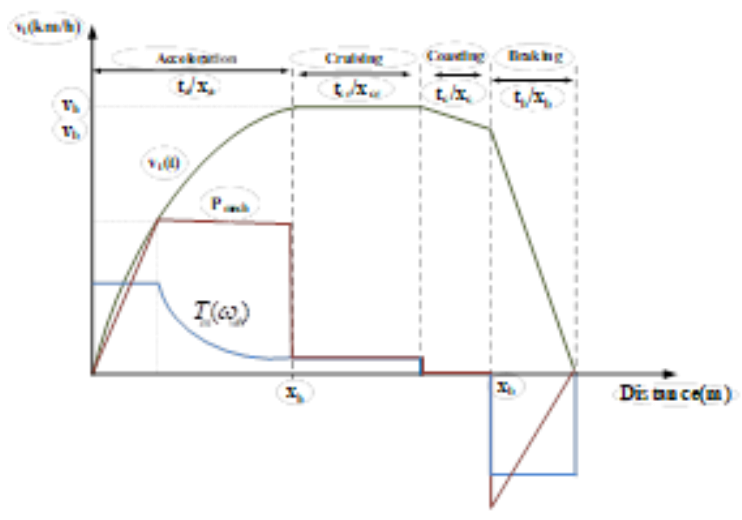

Figure 5. Optimal sequence modes of the train movement with a long station

\subsection{Problem formulation}

The motion of a train along a track can be described by the state equations [5]

$$
\left\{\begin{array}{l}
\frac{d t}{d x}=\frac{1}{v} \\
v \frac{d v}{d x}=u_{t r} f_{t r}(v)-u_{b r} f_{b r}(v)-w_{0}(v)-f_{g r a d}(x)
\end{array}\right.
$$

where $u_{t r}, u_{b r}$ are defined traction and braking control variables of train, both of which are restrained by: $u_{t r} \in[0,1] ; u_{b r} \in[0,1] ; u_{m b} \in[0,1] ; f_{t r}, f_{b r}, f_{\text {grad }}$ are forces per unit mass; traction force applied at the wheels, braking force, mechanical force, gradient force acting on the train.

Therefore, boundary conditions are given by:

$$
\left\{\begin{array}{l}
v(0)=0, v(X)=0, t(0)=0 \\
0 \leq v(x) \leq V(x), 0 \leq t(X) \leq T, 0 \leq x \leq X
\end{array}\right.
$$

where $V(x)$ is the maximum allowable speed, $X$ is the terminal of the train operation; $v(0), v(X)$ are the speed at the beginning, at the end of the route; $T$ is duration of the trip is also given by the timetable.

The objective is to minimize the train's operation energy consumption as the train runs from location $x=0$ to location $x=X$ in time $T$ by controlling the traction force, while ignoring electric braking force since regenerative braking energy is not recovered. The objective function is written as:

$$
J=\int_{0}^{X} u_{t r} f_{t r}(v) d x \rightarrow \min
$$

\subsection{Solution}

By Pontryagin's Maximum Principle finding optimal solutions of an objective function is equivalent to maximizing its Hamiltonian equation. Based on (6), (8), a Hamilton function is formed as:

$$
H=-u_{t r} f_{t r}(v)+p_{1} \frac{1}{v}+p_{2}\left(\frac{u_{t r} f_{t r}(v)-u_{b r} f_{b r}(v)-w_{0}(v)-f_{g r a d}(x)}{v}\right)
$$

where $p_{1}, p_{2}$ are adjoint variables. 
Adjoint variable differential equations are reformed:

$$
\begin{aligned}
& \frac{d p_{1}}{d x}=-\frac{\partial H}{\partial t}=0 \\
& \frac{d p_{2}}{d x}=-\frac{\partial H}{\partial v}=u_{t r} \frac{\partial f_{t r}}{\partial v}+p_{1} \frac{1}{v^{2}}+\frac{p_{2}}{v^{2}}\left[u_{t r} f_{t r}(v)-u_{b r} f_{b r}(v)-w_{0}(v)-f_{g r a d}(x)\right] \\
& -\frac{p_{2}}{v}\left[u_{t r} \frac{\partial f_{t r}}{\partial v}-u_{b r} \frac{\partial f_{b r}}{\partial v}-\frac{\partial w_{0}}{\partial v}\right]
\end{aligned}
$$

Define $p=\frac{p_{2}}{v}$, so $p \cdot v=p_{2}$. Therefore $\frac{d p_{2}}{d x}=\frac{d(p \cdot v)}{d x}=p \frac{d v}{d x}+v \frac{d p}{d x}$

$$
\Rightarrow \frac{d p}{d x}=\frac{1}{v}\left(\frac{d p_{2}}{d x}-p \frac{d v}{d x}\right)
$$

Given $\frac{d v}{d x}=\frac{u_{t r} f_{t r}(v)-u_{b r} f_{b r}(v)-w_{0}(v)-f_{\text {grad }}(x)}{v}$

Therefore, Hamiltonian function is rewritten

$$
H=(p-1) u_{t r} f_{t r}-p u_{b r} f_{b r}-p\left(w_{0}+f_{g r a d}\right)+\frac{p_{1}}{v}
$$

Hamiltonian function is maximized by the following values of $u_{t r}$ and $u_{b r}$ :

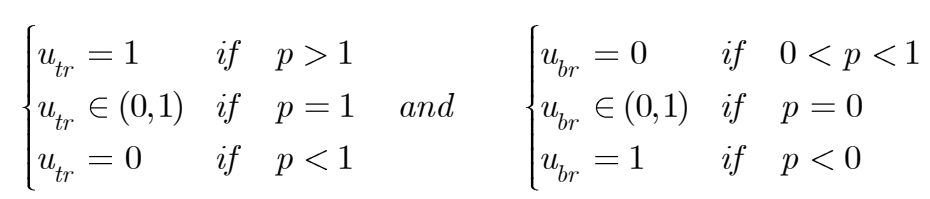

From the above analysis, five optimal control laws are designed

a. Full power (FP): $u_{t r}=1, u_{b r}=0$ when $p>1$

b. Partial power (PP): $u_{t r} \in[0,1], u_{b r}=0$ when $p=1$

c. Coasting (C): $u_{t r}=0, u_{b r}=0$ when $0<p<1$

d. Full braking (FB): $u_{t r}=0, u_{b r}=1$ when $p<0$

e. Partial braking (PB): $u_{t r}=0, u_{b r} \in[0,1]$ when $p=0$

Substitute (11), 14 in (13), finding the differential equation for $p(x)$

$$
\frac{d p}{d x}=\frac{(1-p)}{v} u_{t r} f_{t r}^{\prime}(v)+\frac{p}{v} u_{b r} f_{b r}^{\prime}(v)+\frac{p}{v} w_{0}^{\prime}(v)-\frac{p_{1}}{v^{3}}
$$

From (10), easily, $p_{1}$ is chosen by 0 .

Full power mode: $p>1, u_{b r}=0, u_{t r}=1$, finding accelerating time $t_{a}$, accelerating distance $x_{a}$ Using (17).

$$
\frac{d p}{d x}=\frac{(1-p)}{v} f_{t r}^{\prime}(v)+\frac{p}{v} w_{0}^{\prime}(v)
$$


From (18) finding the differential equation to determine $x_{a}, t_{a}$ :

$$
\left\{\begin{array}{l}
\frac{d x}{d v}=\frac{v}{u_{t r} f_{t r}(v)-w_{0}(v)-f_{\text {grad }}(x)} \\
\frac{d t}{d v}=-\frac{1}{u_{t r} f_{t r}(v)-w_{0}(v)-f_{\text {grad }}(x)}
\end{array}\right.
$$

with initial conditions: $x \quad 0=0, t 0=0$

$$
\text { Coasting speed } v_{b} \text { is calculated as following [38, 39]: } v_{b}=\frac{\psi\left(v_{h}\right)}{\varphi^{\prime}\left(v_{h}\right)}
$$

where $v_{h}$ - hold speed is chosen previously:

$$
\varphi(v)=v \cdot w_{0}(v)=v a+b v+c v^{2}, \psi(v)=v^{2} \cdot w_{0}^{\prime}(v)=v^{2} \quad b+2 c v
$$

From (6) finding the differential equation to determine $x_{c}, t_{c}$ :

$$
\left\{\begin{array}{l}
\frac{d x}{d v}=\frac{v}{-w_{0}(v)-f_{\text {grad }}(x)} \\
\frac{d t}{d v}=-\frac{1}{w_{0}(v)+f_{\text {grad }}(x)}
\end{array}\right.
$$

with $t v=v_{h}=t_{a} ; x v=v_{h}=x_{a}$

Full braking mode: $u_{t r}=0, u_{b r}=1, p<0$, finding braking time $t_{b}$, braking distance $x_{b}$.

$$
\text { Using (17): } \frac{d p}{d x}=\frac{p}{v} f_{b r}^{\prime}(v)+\frac{p}{v} w_{0}^{\prime}(v)
$$

From (6) finding the differential equation:

$$
\left\{\begin{array}{l}
\frac{d x}{d v}=\frac{v}{-u_{b r} f_{b r}(v)-w_{0}(v)-f_{\text {grad }}(x)} \\
\frac{d t}{d v}=\frac{1}{u_{b r} f_{b r}(v)-w_{0}(v)-f_{\text {grad }}(x)}
\end{array}\right.
$$

with $t v=v_{b}=t_{b}, x v=v_{b}=x_{b}$.

In the short journey including three phases: Accelerating $\rightarrow$ coasting $\rightarrow$ braking in accordance with control laws: full power - coasting - full braking.

\section{SIMULATION RESULTS}

The simulation is based on the data of Cat Linh-Ha Dong metro line, Vietnam with simulation parameters of train demonstrated in Table 1, and David's coefficients of train's resistance in Table 2. There are 12 stations, 1 depot, 6 traction substations, and two-side power supply mode. In this paper, simulation results are performed for the first Cat Linh station to the 12th Yen Nghia station with $12.61 \mathrm{~km}$ in length [36]. 
Table 1. Simulation parameters of train

\begin{tabular}{lll}
\hline Parameters of Metro Train & Unit & Value \\
\hline Train gand-up & $2 \mathrm{M} 2 \mathrm{~T}$ & \\
Full load translating mass & $\mathrm{kg}$ & 246700 \\
Number of electrical traction unit & & 08 \\
Max speed & $\mathrm{km} / \mathrm{h}$ & 80 \\
Base speed & $\mathrm{km} / \mathrm{h}$ & 40 \\
Dwell time & $\mathrm{s}$ & 30 \\
Max acceleration/braking rates & $\mathrm{m} / \mathrm{s}^{2}$ & $0.94 / 1$ \\
\hline
\end{tabular}

Table 2. David 's coefficients of train's resistance

\begin{tabular}{cc}
\hline Parameters & Value \\
\hline$a$ & $1.19 \cdot 10^{-2}$ \\
$b$ & $2.56 \cdot 10^{-3}$ \\
$c$ & $1.54 \cdot 10^{-4}$ \\
\hline
\end{tabular}

Because the distance among stations in Cat Linh - Ha Dong metro line is short (the shortest station is $902 \mathrm{~m}$, the longest one is $1480 \mathrm{~m}$ ), operation modes of electrified train are comprised of accelerating $\rightarrow$ coasting $\rightarrow$ braking. Regarding as track conditions, constraints, the speed from a station to another station is different, the slowest speed at $53 \mathrm{~km} / \mathrm{h}$, the highest speed at $73 \mathrm{~km} / \mathrm{h}$, but is always smaller than limit speed $80 \mathrm{~km} / \mathrm{h}$, the optimal trip time is longer 2s indicated in Figure 6 and Figure 7, Table 3. Figure 7 also showed optimal switching points change, so do optimal accelerating, coasting, braking distances significantly. The key result lies in saving energy consumption in optimal speed trajectory up to $10,8 \%$ (practical energy consumption is $176,24 \mathrm{kWh}$, while optimal energy consumption attains $157,19 \mathrm{kWh}$ ).

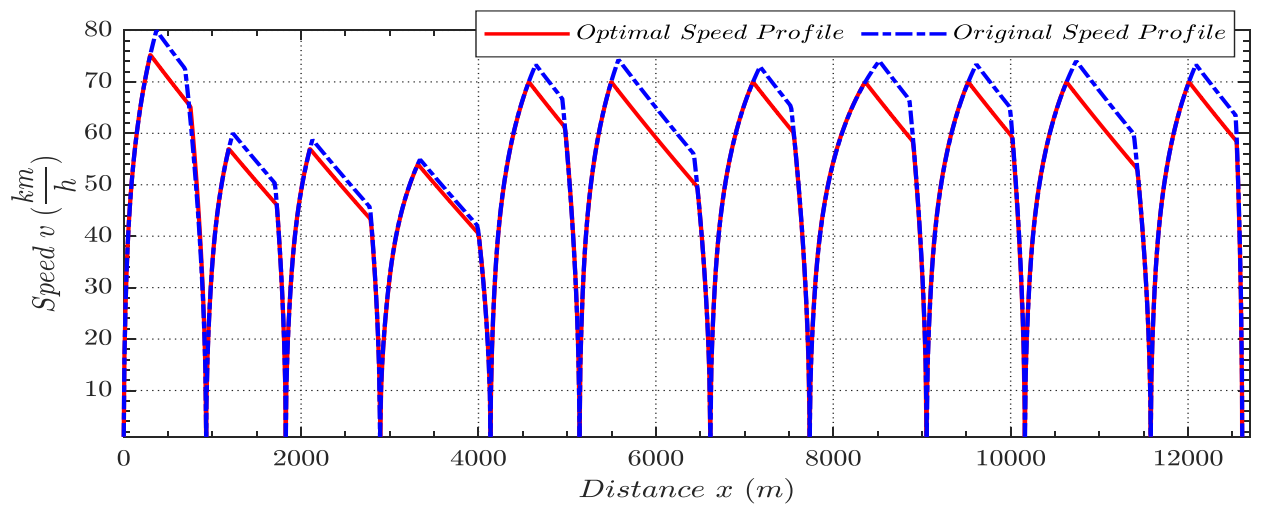

Figure 6. A Comparison of Optimal speed profile and Original speed profile

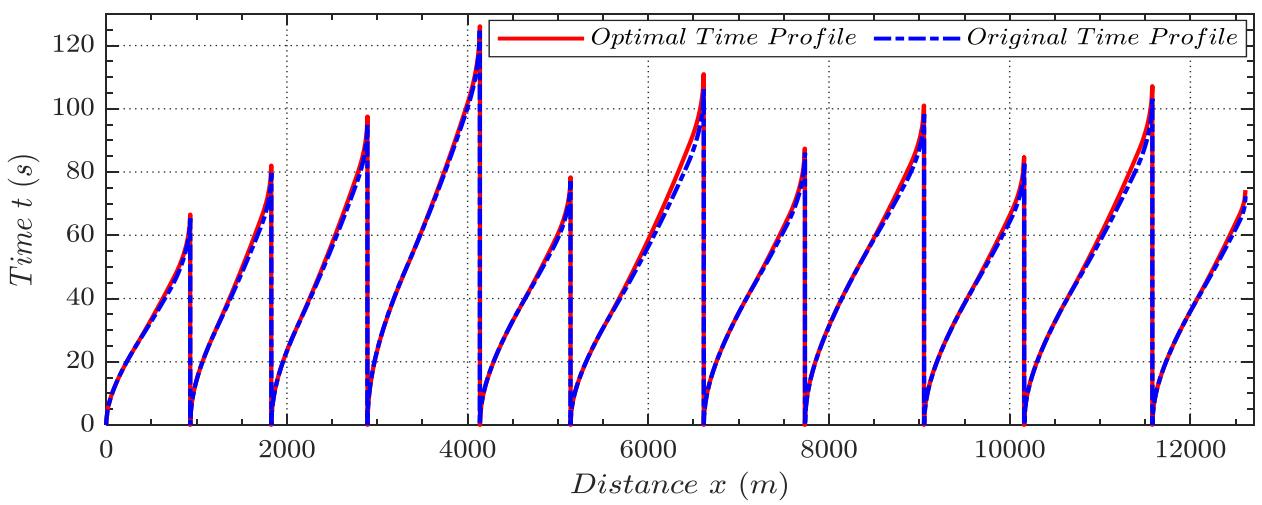

Figure 7. A Comparison of Optimal time profile and Original time profile 
Table 3. Results of a comparison of energy consumption with / without energy optimal strategy

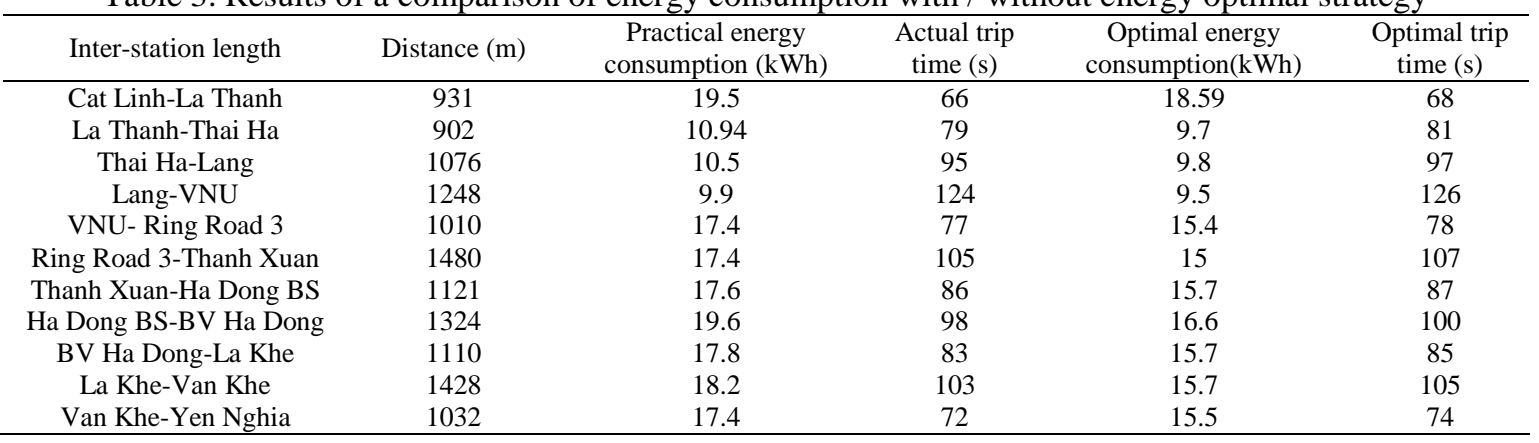

\section{CONCLUSION}

After analyzing advantages and disadvantages of solutions for effective energy usage of electrified train operation, the paper focuses on applying Pontryagin's maximum principle to find the optimal speed profile able to saving energy up to $10,8 \%$ comparison with the original speed profile. The theoretical approach is verified by simulation results including 12 stations of metro line Cat Linh - Ha Dong, Vietnam with three operation phases: accelerating, coasting, braking. Undoubtedly, using PMP determining the optimal speed profile for metro Cat Linh - Ha Dong is going to set the first step for applying the optimal control theory to other metro lines being construction in Vietnam with target: saving energy.

\section{ACKNOWLEDGEMENTS}

The authors would like to thank University of Transport and Communications (UTC) for funding this research under the project code T2019-ĐT-08TĐ.

\section{REFERENCES}

[1] V. R. Vuchic, "Urban transit systems and technology," John Wiley \& Sons, 2007.

[2] A. Nasri, M. F. Moghadam, H. Mokhtari, "Timetable optimization for maximum usage of regenerative energy of braking in electrical railway systems," 2010 International Symposium on Power Electronics Electrical Drives Automation and Motion (SPEEDAM), IEEE, pp. 1218-1221, 2010.

[3] T. Albrecht, S. Oettich, "A new integrated approach to dynamic schedule synchronization and energy-saving train control," WIT Transactions on The Built Environment, vol. 61, pp. 847-856, 2002.

[4] F. Lin, et al., "Multi-train energy saving for maximum usage of regenerative energy by dwell time optimization in urban rail transit using genetic algorithm," Energies, vol. 9, iss. 3, 208, 2016.

[5] X. Sun, H. Lu, H. Dong, "Energy-Efficient Train Control by Multi-Train Dynamic Cooperation," IEEE Transactions on Intelligent Transportation Systems, vol. 18, iss.11, pp. 3114-3121, 2017.

[6] G. M. Scheepmaker, R.M.P. Goverde, L. G. Kroon, "Review of energy-efficient train control and timetabling," European Journal of Operational Research, vol. 257, iss. 2, pp. 355-376, 2017.

[7] Q. Lu, X. Feng, Q. Wang, "Energy-saving optimal control of following trains based on genetic algorithm," Journal of Southwest Jiaotong University, vol. 47, iss. 2, pp. 265-270, 2012.

[8] X. Yang, et al., "A cooperative scheduling model for timetable optimization in subway systems," IEEE Transactions on Intelligent Transportation Systems, vol. 14, iss. 1, pp. 438-447, 2013.

[9] X. Yang, et al., "A two-objective timetable optimization model in subway systems," IEEE Transactions on Intelligent Transportation Systems, vol. 15, iss, 5, pp. 1913-1921, 2014.

[10] M. Peña-Alcaraz, et al., "Optimal underground timetable design based on power flow for maximizing the use of regenerative-braking energy," Proceedings of the Institution of Mechanical Engineers, Part F: Journal of Rail and Rapid Transit, vol. 226, iss. 4, pp. 397-408, 2012.

[11] A. T. H. T. Anh, et al., "Braking energy recuperation for electric traction drive in urban rail transit network based on control super-capacitor energy storage system," Journal of Electrical Systems, vol. 14, iss. 3, pp. 99-114, 2018.

[12] V. Gelman, "Braking energy recuperation," IEEE Vehicular Technology Magazine, vol. 4, iss. 3, pp. 82-89, 2009.

[13] B. Mellitt, Z. S. Mouneimne, C. J. Goodman, "Simulation study of DC transit systems with inverting substations," IEE Proceedings B-Electric Power Applications, vol. 131, iss. 2, pp.38-50, 1984.

[14] Y.-S. Tzeng, R.-N. Wu, and N. Chen, "Electric network solutions of DC transit systems with inverting substations," IEEE Transactions on Vehicular Technology, vol. 47, iss. 4, pp. 1405-1412, 1998.

[15] R. Takagi, "Energy saving techniques for the power feeding network of electric railways," IEEJ Transactions on Electrical and Electronic Engineering, vol. 5, iss. 3, pp. 312-316, 2010.

[16] D. Cornic, "Efficient recovery of braking energy through a reversible dc substation," Electrical Systems for Aircraft, Railway and Ship Propulsion (ESARS), IEEE, 2010. 
[17] D. Cornic, "Efficient recovery of braking energy through a reversible dc substation," 9th World Congress on Railway Research-WCRR, 2011.

[18] Y. Warin, R. Lanselle, M. Thiounn, "Active substation," 9th World Congress on Railway Research-WCRR, 2011.

[19] M. Tomita, et al., "Development of prototype DC superconducting cable for railway system," Physica C: Superconductivity and Its Applications, vol. 470, pp.- S1007-S1008, 2010.

[20] K. Kondo, "Recent energy saving technologies on railway traction systems," IEEJ Transactions on Electrical and Electronic Engineering, vol. 5, iss. 3, pp.- 298-303, 2010.

[21] Toshiba Corporation, "Energy efficient traction system utilizing permanent magnet synchronous motor (PMSM). In: IMechE railway division seminar 'gaining traction in energy efficiency", London, UK, 2012.

[22] E. Khmelnitsky, "On an optimal control problem of train operation," IEEE Transactions on Automatic Control, vol. 45, iss.7, pp. 1257-1266, 2000.

[23] P. Howlett, "The optimal control of a train," Annals of Operations Research, vol. 98, iss.1-4, pp. 65-87, 2000.

[24] R. R. Liu, I. M. Golovitcher, "Energy-efficient operation of rail vehicles," Transportation Research Part A: Policy and Practice, vol. 37, iss.10, pp. 917-932, 2003.

[25] J.-F. Chen, R.-L. Lin, Y.-C. Liu, "Optimization of an MRT train schedule: reducing maximum traction power by using genetic algorithms," IEEE Transactions on Power Systems, vol. 20, iss. 3, pp. 1366-1372, 2005.

[26] P. G. Howlett, P. J. Pudney, X. Vu, "Local energy minimization in optimal train control," Automatica, vol. 45, iss. 11, pp. 2692-2698, 2009.

[27] A. Albrecht, et al., "Optimal train control: analysis of a new local optimization principle," American Control Conference (ACC), 2011, pp. 1928-1933.

[28] Q. Lu, X. Feng, Q. Wang, "Energy-saving optimal control of following trains based on genetic algorithm," Journal of Southwest Jiaotong University, vol.47, iss. 2, pp. 265-270, 2012.

[29] T. Albrecht, A. Binder, C. Gassel, "Applications of real-time speed control in rail-bound public transportation systems," IET Intelligent Transport Systems, vol. 7, iss. 3, pp. 305-314, 2013.

[30] A. Albrecht, et al., "The key principles of optimal train control-Part 1: Formulation of the model, strategies of optimal type, evolutionary lines, location of optimal switching points," Transportation Research Part B: Methodological, vol. 94, pp. 482-508, 2016.

[31] A. Albrecht, et al., "The key principles of optimal train control—Part 2: Existence of an optimal strategy, the local energy minimization principle, uniqueness, computational techniques," Transportation Research Part B: Methodological, vol. 94, pp. 509-538, 2016.

[32] C. Gong, et al., "An integrated energy-efficient operation methodology for metro systems based on a real case of Shanghai metro line one," Energies, vol. 7, iss. 11, pp. 7305-7329, 2014.

[33] J. Yang, et al., "Energy-efficient speed profile approximation: An optimal switching region-based approach with adaptive resolution," Energies, vol. 9, iss. 10, pp. 762-788, 2016.

[34] T. D. Thanh, Q. N. Phung, H. N. Duc, "Power flow analysis for islanded microgrid in hierarchical structure of control system using optimal control theory," Journal of Electrical Systems, vol. 13, iss. 4, pp. 790-805, 2017.

[35] I. Abdou, M. Tkiouat, "Unit Commitment Problem in Electrical Power System: A Literature Review," International Journal of Electrical and Computer Engineering (IJECE), vol. 8, no. 3, pp. 1357-1372, 2018

[36] N. T. M. Chau, "Hanoi Urban Railway Project Cat Linh-Ha Dong Line. Package 1: EPC Contact. Technical Design, Book 2: Traffic organization and operation management," Railway Project Management Unit, Vietnam Railway Administration, 2014.

[37] W. J. Davis, "The tractive resistance of electric locomotives and cars," General Electric, 1926.

[38] J. Yang, et al., "Energy-efficient speed profile approximation: An optimal switching region-based approach with adaptive resolution," Energies, vol. 9, iss. 10, 762, 2016.

[39] N. T. Hai, "Evaluation of effect Pontryagin's Maximum Principle for optimal control train by criteria of energy save," 2010 International Symposium on Computer Communication Control and Automation (3CA), vol. 1, pp. 363-366, 2010.

\section{BIOGRAPHIES OF AUTHORS}

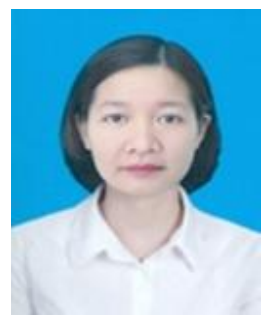

An Thi Hoai Thu Anh received her Engineer (1997), MSc (2002) degrees in Industrial automation engineering from Hanoi University of science and technology. Now, She is a PhD student of Faculty of Electrical and Electronic Engineering under University of Transport and Communications (UTC), Vietnam. Her current interests include Power Electronic Converters, Electric Motor Drive applied for Transportation. 


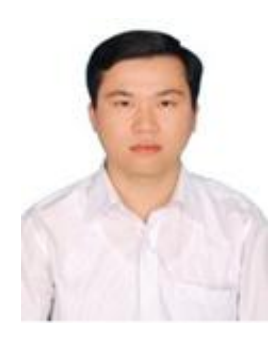

Nguyen Van quyen received his Mechatronic Engineer (2009), MSc (2011) degrees in Engineering Mechanics from Hanoi University of Science and Technology (HUST). Now, He is a lecturer of Department Applied Mechanics of School of Mechanical Engineering under Hanoi University of Science and Technology, Vietnam. His current interests include Dynamics, Control and Optimization of Robots and Mechanisms.

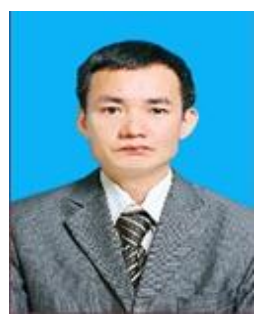

Nguyen Thanh Hai received his Diploma Engineer in 1991. He completed his Ph.D. degree in 1996 in Automation Process (Transport) in the Institute of Control System, Telecommunication and Electrification, Moscow State University of Railway Engineering (MIIT), Russian. He is an Assoc. Prof, Faculty of Electrical and Electronics Engineering, University of Transport and Communications (UTC), Vietnam. His research interests are in the areas of Optimal Control, Power Electronic, Intelligent Transport System (ITS), Signal Processing and Embedded System.

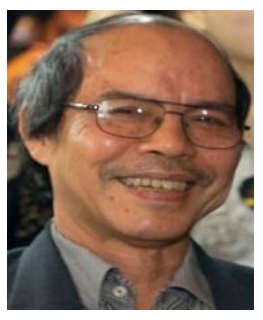

Nguyen Van Lien completed his Ph.D. degree in 1986 in Power Electronics, and Electric Drive from Slovak University of Technology. He is an Assoc. Prof. at School of Electrical Engineering under Hanoi University of Science and Technology. His current interests include Controlling Electric Drive, Power Electronics.

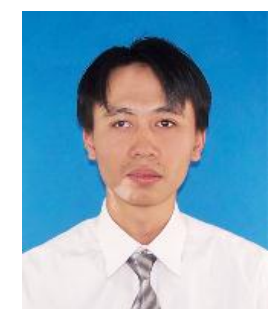

Vu Hoang Phuong received his B.S., M.S., and Ph.D. degrees from Hanoi University of Science and Technology, Vietnam, in 2006, 2008, and 2014, respectively, all in Control Engineering and Automation. Since 2006 he has been employed at Hanoi University of Science and Technology, where he is a lecturer and researcher at School of Electrical Engineering. His research interests include Modeling and Controlling of Power Electronics Converters for applications like as Photovoltaic, Wind system, Electrical Machine Drive. 